\title{
Dinâmicas da agenda do aborto no Senado Federal: de 1988 a outubro de 2020
}

\author{
Maria Clara Figueiredo Dalla Costa Ames ${ }^{1}$ \\ MAURICIO CUSTÓdio SERAFIM ${ }^{1}$ \\ MARCELLO BeCKERT ZAPPELLINI ${ }^{1}$ \\ ANDRE COSTA COLONETtI ${ }^{1}$
}

\author{
${ }^{1}$ Universidade do Estado de SANTA CATARINA (UDESC) / CENTRO dE CIÊNCIAS DA AdMINISTRAÇÃo E SOCIOECONÔMICAS, DEPARTAMENTO DE
} ADMINISTRAÇÃO PÚBLICA, FLORIANÓPOLIS - SC, BRASIL

\begin{abstract}
Resumo
O tema do aborto é uma complexa questão filosófica e moral, que, na análise de políticas públicas, tem sido tratado como uma política de moralidade. Este artigo busca analisar as dinâmicas da agenda política do aborto no Senado Federal brasileiro, tendo como base a abordagem da Teoria do Equilíbrio Pontuado. Do enfoque de Baumgartner e Jones (1993), são analisadas a atenção e a imagem dada ao aborto entre os anos de 1988 e outubro de 2020, visando entender quais fatores interferem na formação da agenda. Por meio de pesquisa documental e análise de conteúdo, foram analisadas 33 proposições legislativas, 295 pronunciamentos e seis audiências públicas, sendo classificada a imagem da política presente nesses elementos conforme o tom: "neutro", "favorável" ou "contrário" ao aborto. Os resultados revelam as imagens coexistentes da questão em argumentos e preferências de senadores, partidos políticos e participantes em audiências, internos e externos ao governo. Há uma tendência de estabilidade no Senado com predominância de tom contrário ao aborto, mas novas imagens para o enquadramento do assunto são discutidas, posicionando o aborto como questão de saúde pública e como direito, simultaneamente ao seu entendimento como crime, algo também presente em eventos focalizadores como as audiências públicas. Além disso, senadores e atores externos apontam o STF como fórum que adiciona mudanças na legislação sobre o aborto, a exemplo da ADPF 54 (STF, 2013) e da ADPF 442 (STF, 2017), ainda em aberto. Sugere-se que a Suprema Corte seja abordada por futuros estudos sobre dinâmicas da agenda.
\end{abstract}

Palavras-chave: Aborto. Formação da agenda. Política de moralidade. Senado Federal.

\section{Dynamics of the abortion agenda in the Brazilian Senate from 1988 to October 2020}

\section{Abstract}

Abortion is a complex philosophical and moral issue treated as a morality policy in the public sphere. This article aims to analyze the dynamics of shaping the abortion political agenda in the Brazilian Senate, based on the punctuated equilibrium theory. Adopting the approach by Baumgartner and Jones (1993), the study explores the attention and image given to abortion between 1988 and October 2020 to understand which factors affect the policy's agenda-setting. Documentary research and content analysis were used to examine 33 legislative propositions, 295 pronouncements, and six public hearings, classifying the policy image as neutral, pro-choice, or pro-life. The results reveal coexisting images in the arguments and preferences of senators, political parties, and participants in public hearings (both internal and external to the government). There is a trend towards stability in the Senate with a predominance of pro-life positions. However, at the same time that policy image of abortion as a crime were present in focalizing events such as public hearings, new images for framing the issue could be observed and have been discussed, addressing abortion as a public health issue and as a right. In addition, senators and external actors point to the Brazilian Supreme Court as a forum that can push for changes in the abortion legislation, such as in the example of the Claim of Non-compliance with Fundamental Precept 54 (ADPF 54) (STF, 2013) and ADPF 442 (STF, 2017), the latter is still in discussion in the court. Future studies on this agenda's dynamics should address the discussions under development in the Brazilian Supreme Court.

Keywords: Abortion. Agenda-setting. Morality policy. Federal Senate.

\section{Dinámica de la agenda del aborto en el Senado Federal: de 1988 a octubre de 2020}

\section{Resumen}

El tema del aborto es una cuestión filosófica y moral compleja que, en el análisis de las políticas públicas, se ha tratado como una política de moralidad. Este artículo busca analizar la dinámica de la agenda política del aborto en el Senado Federal brasileño, a partir del enfoque de la teoría del equilibrio puntuado. Basándose en el enfoque de Baumgartner y Jones (1993), este artículo analiza la atención y la imagen que se ha dado al aborto entre 1988 y octubre de 2020, con el objetivo de entender qué factores interfieren en la formación de la agenda. Mediante la investigación documental y el análisis de contenidos, se analizaron 33 propuestas legislativas, 295 pronunciamientos y seis audiencias públicas, clasificando la imagen de la política presente en estos elementos según el tono "neutro", "favorable" o "contrario" al aborto. Los resultados revelan la coexistencia de imágenes de la cuestión basadas en argumentos y preferencias de senadores, partidos políticos y participantes en audiencias, tanto internos como externos al gobierno. Existe una tendencia a la estabilidad en el Senado con un predominio del tono contrario al aborto, pero se discuten nuevas imágenes para enmarcar el tema, posicionando el aborto como una cuestión de salud pública y como un derecho, simultáneamente a su comprensión como delito, algo también presente en eventos focales como las audiencias públicas. Además, senadores y actores externos señalan al Supremo Tribunal Federal como un foro que añade cambios a la legislación sobre el aborto, como ejemplifican el ADPF 54 (STF, 2013) y el APFF 442 (STF, 2017), aún en abierto. Se sugiere que futuros estudios aborden la dinámica de la agenda del Supremo Tribunal.

Palabras clave: Aborto. Agenda-setting. Política de moralidad. Senado Federal. 


\section{INTRODUÇÃO}

No campo de políticas públicas, a questão do aborto é um problema conflituoso, polarizador e para o qual o consenso é muito difícil, se não impossível (Mooney, 2000; Secchi, 2016). Estudiosos têm discutido sua relação com direitos fundamentais, dignidade humana, autonomia decisória, e decisões na esfera pública (Dall'Agnol \& Tonetto, 2015; Dworkin, 2009; Finnis, 2019; Ribeiro \& Pinheiro, 2017), considerando aspectos filosóficos, morais, jurídicos e biológicos.

No contexto brasileiro são encontrados grupos de interesse que discutem o direito ao aborto - ou direito de escolha - e o direito à vida (Miguel, Biroli \& Mariano, 2017), nas posições conhecidas respectivamente como "pró-escolha" e "pró-vida" (Munson, 2018). Tais posicionamentos não se restringem à fronteira nacional, interagindo com dinâmicas transnacionais.

Atualmente o aborto tem sido tratado na opinião pública como uma questão da área de saúde pública. No entanto, trata-se de um aspecto da vida humana, sensível à reflexão sobre a vida e a morte. É uma questão moral que se manifesta em um conflito de valores nas decisões políticas (Knill, 2013). Por essas e outras razões, tem sido definido como política de moralidade, ou morality policy (Engeli, Green-Pedersen \& Larsen, 2012; Mooney, 2000; Studlar \& Burns, 2015).

O debate na Câmara de Deputados tem sugerido fatores para diretrizes de políticas públicas, como o planejamento familiar, a saúde da mulher e os direitos reprodutivos e sexuais, seguindo um posicionamento majoritariamente contrário ao aborto (Miguel et al., 2017). No fórum do Supremo Tribunal Federal (STF), estudos analisam deliberações sobre o aborto (Machado \& Cook, 2018; Oliveira, Montenegro \& Garrafa, 2005). De outros países, há pesquisas que abordam conjuntamente a agenda política e da mídia (Chaqués-Bonafont, Palau \& Baumgartner, 2015). No contexto do Senado brasileiro, algumas teses e artigos analisam aspectos legais e do discurso (p. ex.: Souza, Feltrin \& Velho, 2019), mas por lentes teóricas distintas dos elementos do equilíbrio pontuado, pela qual se pode abordar elementos como fórum, atores, atenção e imagem da política. Em políticas de moralidade, mudanças parecem ser lentas e incrementais (Studlar \& Burns, 2015), embora a realidade brasileira pareça revelar fatores que provocam mudanças repentinas.

O objetivo deste artigo, portanto, é analisar as dinâmicas na formação da agenda da política do aborto, limitando-se ao Senado entre os anos de 1988 e outubro de 2020, com base na abordagem de Baumgartner e Jones (1993). O período histórico de análise se inicia com a promulgação da atual Constituição Federal e se encerra na atualidade.

Busca-se responder à seguinte pergunta: como e quais elementos interferem na formação da agenda da política de aborto no Senado Federal? Com isso procura-se contribuir para o entendimento da política de moralidade do aborto, iniciando-se pelas considerações do Senado, por ser um dos fóruns representativos da sociedade, por integrar o processo legislativo como a "Câmara Alta" desse poder - pelo qual se delibera sobre proposições de lei - e por possivelmente ser um fórum visado por empreendedores de política. Para isso, serão analisados o número e o tom de proposições legislativas, de pronunciamentos dos senadores e de participantes externos e internos em audiências públicas, com a abordagem também sobre preferências partidárias. Este estudo contribui para o entendimento de como ocorrem mudanças na política de moralidade do aborto, que podem ser gradativas e incrementais, ou súbitas e radicais, a depender da adição de fóruns de política e grau de participação nos debates. Nas dinâmicas da agenda do aborto no contexto do Senado, interferem fatores como novas imagens dadas à questão, a busca pelo STF via Arguição de Descumprimento de Preceito Fundamental (ADPF) diante da tendência à estabilidade na casa, bem como maior participação na formulação de políticas públicas por atores internos e externos ao governo, durante seis audiências públicas sobre a questão, consideradas aqui como eventos focalizadores.

Além dessa introdução, este artigo contém mais quatro seções. Primeiramente, é apresentado um referencial teórico sobre a política de moralidade do aborto, formação e dinâmicas da agenda. Em seguida, são descritos os procedimentos metodológicos, para então serem discutidos os resultados da pesquisa. As limitações do estudo e possibilidades de pesquisas futuras são ponderadas nas considerações finais. 


\section{A POLÍTICA DE MORALIDADE DO ABORTO}

Questões morais ou morality issues vêm recebendo uma crescente atenção no âmbito das políticas públicas (Engeli et al., 2012; Studlar \& Burns, 2015). Vários analistas têm aceitado que essas questões possuem similaridade de conteúdo, framing e/ou processo, o que merece ser considerado como uma categoria comum (Engeli et al., 2012; Knill, 2013; Mooney, 2001; Schwartz \& Tatalovich, 2009; Smith \& Tatalovich, 2003; Roh \& Berry, 2008; Ryan, 2014).

Políticas de moralidade estão relacionadas a aspectos fundamentais, como vida e morte, reprodução e casamento, e frequentemente interagem com valores religiosos. $\mathrm{O}$ aborto tem funcionado como a principal questão diante das demais, impulsionando a politização de outros problemas morais (Studlar \& Burns, 2015).

A teoria da política de moralidade oferece duas correntes principais (Engeli et al., 2012). A primeira tem buscado investigar políticas morais no contexto americano, tratando de questões como: aborto, pena de morte, eutanásia, pesquisa com células-tronco, comércio de órgãos humanos (como, por exemplo, em Mooney, 2001; Tatalovich \& Daynes, 2011). A segunda é uma literatura comparativa, com foco na explicação da variação entre países quanto a seus problemas de moralidade (como tratado por Banchoff, 2011; Engeli, 2009).

Mooney (2000) descreve as principais características da política de moralidade: abrange grande participação de pessoas, representa um conflito de princípios ou valores básicos defendidos por distintos grupos ou coalisões, é tecnicamente simples enquanto sanção legal, pois define o que é certo ou errado para uma comunidade e, finalmente, envolve questões salientes e polêmicas. Elas se encaixam no conceito de políticas distributivas, de acordo com a classificação de Lowi (como citado em Birkland, 2005), pois representam uma aplicação remota dos poderes coercitivos do Estado (o poder público não poderia obrigar uma pessoa a abortar contra a sua vontade) a indivíduos específicos, não no geral (Smith, 2002). Essas políticas são eminentemente descentralizadas, o que indica que o foco de atuação é o Congresso e não a Presidência da República (Smith \& Larimer, 2009), e se aplicam ao comportamento dos indivíduos (Dodds, 2013; Smith \& Larimer, 2009). Entretanto, uma interpretação alternativa indica que poderiam ser regulatórias, uma vez que mantêm o foco no comportamento individual e envolvem a suspensão de uma aplicação direta do poder coercitivo do Estado por este já não mais penalizar o aborto e também se situam no plano da discussão no Congresso (Dodds, 2013; Smith, 2002; Smith \& Larimer, 2009). Essa discussão ilustra bem uma grande dificuldade das políticas de moralidade, qual seja, até que ponto se está efetivamente usando o aparato coercitivo estatal na promoção de comportamentos desejáveis ou na eliminação de comportamentos indesejáveis.

A corrente de estudos comparativos (Engeli et al., 2012) tem encontrado grande importância no papel de atores religiosos em políticas de moralidade. Engeli et al. (2012) buscam entender a politics por trás das escolhas políticas considerando a influência da religião e do papel de atores religiosos, como a Igreja Católica (Calkin \& Kaminska, 2020). Por isso, comparam países mais secularizados com aqueles de características confessionais, nos quais a religião influencia na configuração partidária e em coalisões (Engeli et al., 2012).

Para Studlar e Burns (2015), a política de moralidade se define pelo seu conteúdo ou por seu processo. Os autores encontram o surgimento da política do aborto em 24 democracias ocidentais por volta de 1955, com duração de aproximadamente 50 anos. Em termos de conteúdo, Studlar e Burns (2015) sugerem uma similaridade entre as agendas, com forte tendência para a sua permissão. Studlar e Burns (2015) afirmam que, no estudo da política de moralidade, uma mudança representa uma alteração de direção dramática para muitas pessoas, criando ganhadores e perdedores em valores endossados pelo governo. Em virtude disso, mudanças ocorrem em passos gradativos e incrementais, devido a fatores culturais, institucionais e internacionais, como no caso das 24 nações em análise por Studlar e Burns (2015), em quais tal política se desenvolveu ao longo de 50 anos.

\section{Formação e dinâmicas da agenda}

O termo 'agenda' é utilizado como um recurso heurístico para estudar o processo em que uma questão passa a receber atenção por parte da comunidade de política pública (Wu, Ramesh, Howlett \& Fritzen, 2014). Neste artigo foi adotada a definição de agenda governamental sugerida por Kingdon (2003), que a conceitua como o conjunto de assuntos para os quais o governo e os atores a ele ligados dedicam atenção em determinado momento. A escolha dessa definição se associa ao fato de que o modelo de Baumgartner e Jones (2015) a adota explicitamente. 
A formulação da agenda é construída por iniciativas de atores governamentais e não governamentais, atuando sobre os fluxos: de problemas (indicadores e diagnóstico), de políticas (soluções) e o político (forças e interesses) (Capella, 2018; Kingdon, 2003). Atores que atuam fortemente por uma política são definidos como empreendedores de políticas públicas (Anderson, 2003; Capella, 2016; Kingdon, 2003). Eles podem contribuir para a convergência entre os fluxos, na medida em que ajustam soluções ao problema, dão novos entendimentos à questão e disseminam uma imagem da política (Capella, 2016). Além disso, podem construir coalizões e, estrategicamente, disseminar informações para promover mudanças na agenda (Anderson, Deleo \& Taylor, 2019). Na interação entre os atores e na convergência desses fluxos, pode se abrir uma janela de oportunidade em que se introduzem mudanças na política (Kingdon, 2003; Zappellini, 2014).

Com o modelo de Baumgartner e Jones (1993), analisa-se a evolução das políticas públicas ao longo do tempo por meio da noção de equilíbrio pontuado, o qual é marcado por longos períodos de estabilidade interrompidos por mudanças relativamente súbitas em termos da atenção e do entendimento dos problemas de política. O estágio de discussão de uma questão pode influenciar na tendência de mudança ou estabilidade. Estágios iniciais estão mais associados às preferências do público e são mais suscetíveis a mudanças. Estágios mais avançados revelam mais resistência ou "viscosidade" na promoção de mudanças em dada política. Características institucionais contribuem para essa resistência (Baumgartner, Jones \& Wilkerson, 2011). É o caso de vários estágios de votos para aprovação de um projeto de lei. Além das instituições, outros fatores podem interferir nas dinâmicas da agenda, tais como o governo vigente, culturas e crenças, além de atores externos (Chaqués-Bonafont et al., 2015). Por exemplo, a Igreja Católica tem influenciado na política do aborto por ser contra a sua prática, enquanto os movimentos feministas por serem favoráveis (Calkin \& Kaminska, 2020; Munson, 2018).

Para análise da formação da agenda, Baumgartner et al. (2011) demonstram que o intervalo de tempo pode contribuir para identificar o que vem provocando mudanças na política: se é um fator ideológico, transnacional, partidário ou dinâmico. Ativistas, litigantes ou eleitores podem trazer itens para a agenda de governo. No entanto, é mais comum que os itens da agenda provenham de atores coletivos organizados (Wu et al., 2014), denominados grupos de interesse: organizações religiosas, empresas, sindicatos, associações ou think tanks. Como observam Baumgartner e Jones (2015), a informação é um elemento central na política; consequentemente, observa-se que os grupos de interesse operam com estratégias de informação, buscando chamar a atenção para elementos do debate que possam sustentar seus pontos de vista.

Baumgartner e Jones (1993) oferecem quatro elementos ou dimensões para descrever a definição de conflito: (1) atenção: o tamanho da audiência e o escopo do debate ao longo do tempo; (2) atores: a constelação de atores envolvidos, ou subsistema de política; (3) imagem, ou definição do problema: o enquadramento que se dá à política sob uma perspectiva, assumindo, por exemplo, um tom contrário, favorável ou neutro à mudança; e (4) fórum (institutional venue): espaço institucional em que a discussão da política ocorre. Os atores podem tentar mover as questões para um fórum diferente e desestabilizar o equilíbrio existente criando mudança na política (Engeli et al., 2012). Nesse caso, os atores agem como empreendedores de política que buscam aproveitar as janelas de oportunidade.

Chaqués-Bonafont et al. (2015) analisam as mudanças na atenção e na imagem da política do aborto no parlamento espanhol e em dois jornais espanhóis, ao longo dos anos, para entender a relação entre imagem, partidos políticos e mídia. Sustentam que não somente a imagem e as preferências influenciam na estabilidade e mudança, mas também a mudança de valores religiosos e fatores institucionais. O controle do governo por partidos de esquerda ou direita e o tipo de governo são importantes preditores do acesso à agenda e de mudança na política.

A influência da mídia e os argumentos em pronunciamentos também aparecem em estudos brasileiros, embora não se utilizem do arcabouço das dinâmicas da agenda. São abordados argumentos dos atores políticos (Miguel et al., 2017) e o papel da mídia na formação da agenda e em debates eleitorais de 2010 (Barreras, 2013; Mantovani, 2014). O direito à vida tem sido o argumento mais citado nos pronunciamentos na Câmara dos Deputados, $61 \%$ dos pronunciamentos são favoráveis à manutenção do status quo (Miguel et al., 2017). Como demonstra Birkland (2005), monopólios de política são usuais no campo das políticas públicas, mas podem ser quebrados pela atuação de meios de comunicação, de grupos de interesse ou de partidos políticos.

Outros ainda discutem as deliberações ocorridas no STF, como na ADPF 54 (STF, 2013), em que se votou a favor da impunibilidade do aborto em caso de bebês anencéfalos (Machado \& Cook, 2018). Desde 2007, também, tramitam duas ADPFs envolvendo a "interrupção voluntária da gestação" até a sua 12a semana e no caso de microcefalia. Audiências foram realizadas em agosto de 2018, com a participação de grupos de interesse (STF, 2017); o assunto continua em discussão. A entrada do STF demonstra uma quebra do monopólio da política, uma vez que a discussão sobre o aborto, antes circunscrita ao Congresso, passou a incorporar também o Judiciário. 


\section{PROCEDIMENTOS METODOLÓGICOS}

Nesta seção são descritos os procedimentos metodológicos de coleta, análise e descrição dos resultados. Foi realizada uma pesquisa documental para coleta de dados nos registros disponibilizados na plataforma online do Senado Federal e consequente análise quantitativa e qualitativa dos dados, por meio de exame de conteúdo, buscando examinar o tom em relação ao aborto e o conteúdo dos argumentos, tais como os associados a pronunciamentos de atores, proposições de leis e eventos citados (Bardin, 2009).

A pesquisa abrange o período entre os anos de 1988 e outubro de 2020, um recorte temporal condizente com a abordagem de Baumgartner et al. (2011), com o objetivo de analisar os desdobramentos da Constituição Federal de 1988. A busca pelo termo "aborto" foi realizada em dezembro de 2017 e atualizada posteriormente para incluir os registros até 15 de outubro de 2020. Termos correlatos como "abortamento" e "interrupção voluntária da gravidez" também foram considerados. A busca pelos termos "óbitos fetais" ou "mortalidade fetal" não encontrou registros.

Tendo como foco a atenção e a imagem atribuída à política de moralidade do aborto durante o período, optou-se pelo modelo teórico-analítico exposto no Quadro 1 para condução da pesquisa.

\section{Quadro 1}

\section{Modelo teórico-analítico}

\begin{tabular}{|c|c|c|}
\hline $\begin{array}{l}\text { Elemento teórico, conforme } \\
\text { Teoria do Equilíbrio Pontuado }\end{array}$ & $\begin{array}{l}\text { Elementos } \\
\text { empíricos }\end{array}$ & $\begin{array}{l}\text { Dados } \\
\text { selecionados }\end{array}$ \\
\hline - Fórum & - Senado Federal. & $\begin{array}{l}\text { - Período: de } 1988 \text { a } \\
15 \text { de out. } 2020 \text {. }\end{array}$ \\
\hline - Atenção & $\begin{array}{l}\text { - Produção legislativa por ano. } \\
\text { - Pronunciamentos de senadores por ano. } \\
\text { - Audiências públicas realizadas. }\end{array}$ & $\begin{array}{l}\text { - } n=33 \text { proposições. } \\
\text { - } n=295 \text { pronunciamentos. } \\
\text { - } n=6 \text { audiências. }\end{array}$ \\
\hline - Atores & $\begin{array}{l}\text { - Atores internos: senadores que pronunciam } \\
\text { ou encaminham proposições sobre o aborto. } \\
\text { - Atores externos: participantes de audiências } \\
\text { públicas a atores citados. }\end{array}$ & $\begin{array}{l}\text { - } n=95 \text { senadores, ao longo do } \\
\text { período. } \\
\text { - } n=45 \text { atores internos e } \\
\text { externos. }\end{array}$ \\
\hline $\begin{array}{l}\text { - Imagem } \\
\text { - Subcategoria: tom da política } \\
\text { (preferência). }\end{array}$ & $\begin{array}{l}\text { - Pronunciamentos favoráveis } \\
\text { à descriminalização do aborto. } \\
\text { - Pronunciamentos contrários. } \\
\text { - Pronunciamentos neutros. } \\
\text { - Número de pronunciamentos } \\
\text { por partido político. }\end{array}$ & $\begin{array}{l}\text { - Pronunciamentos, por ano, } \\
\text { classificados por tom da política. } \\
\text { - Conteúdo dos pronunciamentos: } \\
\text { atores, legislações, eventos e } \\
\text { acontecimentos citados. }\end{array}$ \\
\hline
\end{tabular}

Fonte: Elaborado pelos autores.

Na plataforma do Senado Federal, a busca restringiu-se a: (1) proposições de leis (43 registros), visto que novas propostas legislativas indicam tentativas de mudar a agenda (Anderson et al., 2019) e refletem o grau de atenção sobre a questão do aborto; (2) pronunciamentos de senadores (458), considerando o tom desses registros, se são "contrários", "favoráveis" ou "neutros" em relação ao aborto, e (3) audiências públicas realizadas no período. Dados básicos de proposições e pronunciamentos foram categorizados em uma planilha Excel contendo: (a) proposições - autoria, origem, partido, número do projeto, tom, ano, ementa, último local de tramitação, último estado, relator e link de acesso; (b) pronunciamentos - nome do senador, sexo, partido, data, tom do pronunciamento, trecho que explicita o tom do pronunciamento e link de acesso. Para análise das audiências, foram acessados notícias e conteúdo das audiências públicas visando identificar participantes.

Com a leitura das 43 proposições de lei, foram selecionadas 33 que tratam de aspectos legais relacionados ao aborto. As restantes foram retiradas da amostra, pois tratam de outros assuntos, como trânsito, trabalho e meio ambiente. Dos 458 pronunciamentos sobre o aborto, 22 não estão disponíveis, a maioria data do ano de 1988; outros 141 registros citam o termo, mas não tratam da questão. Para essa análise foram selecionados 295 pronunciamentos disponíveis, por discutirem diretamente o aborto, sua legislação e implicações. 
A análise do tom atribuído à política - favorável, contrário ou neutro-ocorreu em três etapas. Primeiramente, os pronunciamentos foram lidos individualmente, em ordem cronológica. No segundo passo, realizado por um segundo pesquisador, foram revistos os pronunciamentos sobre os quais restavam dúvidas em relação ao tom do posicionamento. Na terceira etapa, fez-se uma análise conjunta dos pronunciamentos, por senador e por partido político. $\mathrm{O}$ tom das proposições de lei foi analisado como favorável quando os projetos buscavam alterar a legislação vigente para descriminalizar o aborto ou ainda incluir situações em que pode ser permitido; o tom contrário corresponde aos trabalhos que mantêm a legislação vigente ou buscam criminalizar o aborto ou a sua incitação. As proposições e pronunciamentos neutros são de caráter procedimental e técnico, não assumem um tom predominante.

A análise do conteúdo dos materiais das audiências públicas permitiu identificar participantes internos e externos ao governo, bem como o tom dado para descrever o problema e soluções. Foram encontradas oito audiências relacionadas ao tema, dentre as quais seis foram selecionadas devido à sua relação direta com o tema. A seguir são apresentados os principais resultados da pesquisa, considerando o número e tom de proposições e pronunciamentos ao longo dos anos, as soluções legislativas propostas e argumentos elencados, e atores participantes das audiências públicas.

\section{RESULTADOS}

Nesta seção são apresentados os resultados da análise de proposições, pronunciamentos e audiências. Das 33 proposições de leis selecionadas, cinco são Requerimentos para a Realização de Audiências Públicas para a Comissão de Direitos Humanos (RDH), cinco são Requerimentos de Informações (RQS), uma trata-se da Sugestão de lei número 15 (SUG 15, 2014), e as demais são Projetos de lei do Senado (PLS), os quais versam, em sua maioria, sobre os artigos 124 a 128 do Decreto-Lei 2.848 (1940) do Código Penal Brasileiro, nos casos em que se pune ou não o aborto. O Gráfico 1 apresenta o número e o tom das proposições ao longo do tempo.

\section{Gráfico 1}

\section{Número e tom das proposições legislativas do senado sobre o aborto}

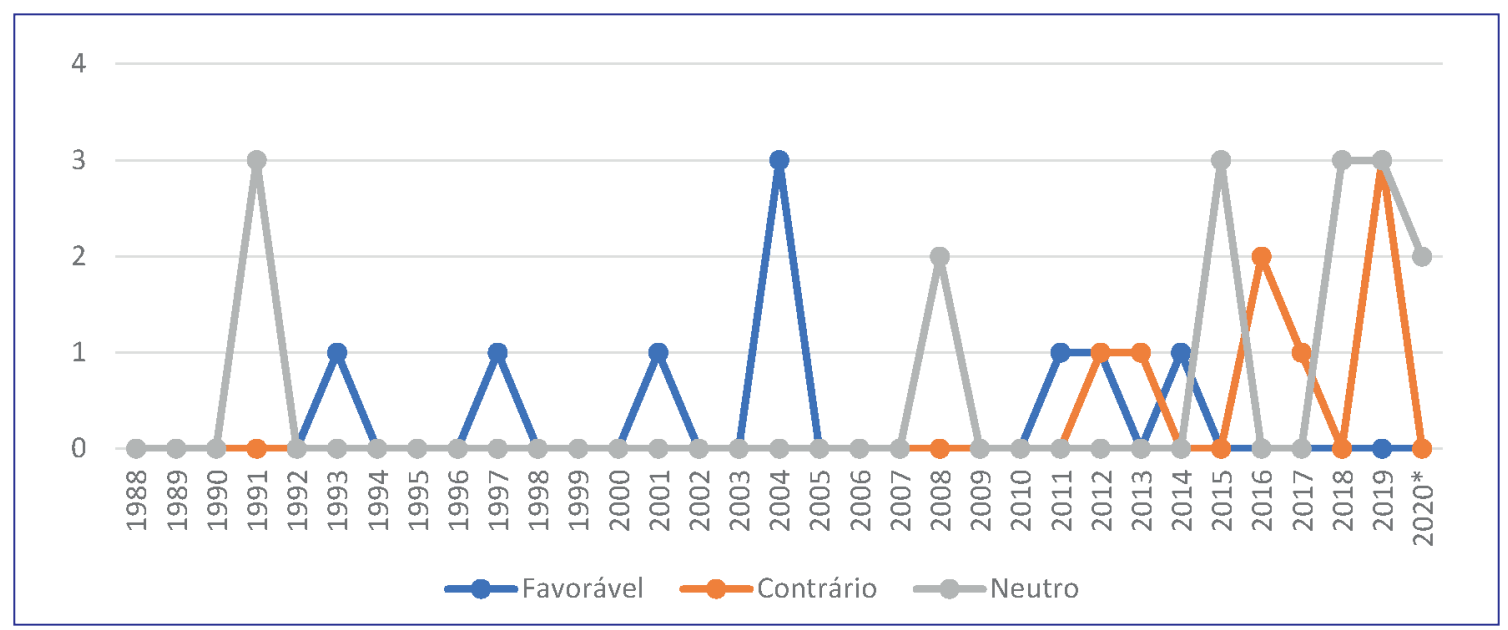

Nota: * contempla as proposições iniciadas até 15 outubro de 2020.

Fonte: Elaborado pelos autores.

As proposições legislativas favoráveis ao aborto se concentram entre os períodos de 1993 a 2004 e de 2011 a 2014. Ao longo desses períodos, nove iniciativas de lei no Senado Federal foram favoráveis à descriminalização do aborto, constituindo a maioria propostas de mudanças no Decreto-Lei 2.848 (1940). As oito propostas contrárias ao aborto surgem a partir de 2012 e procuram manter a regulação vigente, ou, ainda, criminalizar o induzimento e a instigação ao aborto, o anúncio de meio abortivo e o aborto em qualquer fase da gestação. Entre as 16 proposições classificadas como neutras, foram encontrados quatro projetos de lei, dos quais dois versam sobre a Lei no 9.263 (1996) de planejamento familiar. 
Dinâmicas da agenda do aborto no Senado Federal: de 1988 a outubro de 2020
Maria Clara Figueiredo Dalla Costa Ames | Mauricio Custódio Serafim Marcello Beckert Zappellini | Andrei Costa Colonetti

O Quadro 2 apresenta autores e respectivas legendas partidárias das proposições, bem como respectivos códigos e ementas, organizados conforme o tom da política.

\section{Quadro 2}

Proposições legislativas do senado sobre aborto segundo tom, autoria e ementa (1988 - 15 out. 2020)

\begin{tabular}{|c|c|c|}
\hline Tom & Autoria & Proposição e ementa \\
\hline \multirow{9}{*}{ 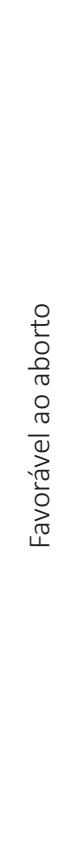 } & $\begin{array}{l}\text { Eva Blay } \\
\text { (PSDB/SP) }\end{array}$ & $\begin{array}{l}\text { PLS 78/1993 - disciplina a prática do aborto, } \\
\text { altera o Decreto-Lei } 2848 \text { (1940). }\end{array}$ \\
\hline & $\begin{array}{l}\text { Carlos Patrocínio } \\
\qquad(\mathrm{PFL}, \mathrm{TO})\end{array}$ & $\begin{array}{l}\text { PLS 28/1997 - altera Lei } 9.263 \text { (1996) } \\
\text { de planejamento familiar. }\end{array}$ \\
\hline & $\begin{array}{l}\text { Prof. Luizinho } \\
\text { (PT/SP) - Câmara }\end{array}$ & $\begin{array}{l}\text { PLS 18/2001 - dispõe sobre a obrigatoriedade de servidores de Delegacias } \\
\text { de Polícia informarem as vítimas de estupro sobre o direito de aborto legal. }\end{array}$ \\
\hline & $\begin{array}{l}\text { Duciomar Costa } \\
\quad(\text { PTB/PA) }\end{array}$ & $\begin{array}{l}\text { PLS 183/2004 - altera o Decreto-Lei } 2.848(1940) \\
\text { para incluir caso de anencefalia fetal. }\end{array}$ \\
\hline & $\begin{array}{l}\text { Mozarildo Cavalcanti } \\
\quad \text { (PPS/RR) }\end{array}$ & $\begin{array}{l}\text { PLS 227/2004 - altera o art. } 128 \text { do Decreto-Lei } 2.848 \text { (1940) para } \\
\text { não punir a prática do aborto realizado por médico em caso de anencefalia. }\end{array}$ \\
\hline & $\begin{array}{l}\text { Marcelo Crivella } \\
\qquad(\mathrm{PL} / \mathrm{RJ})\end{array}$ & $\begin{array}{l}\text { PLS 312/2004 - altera o Decreto-Lei } 2.848 \text { (1940) para incluir hipótese } \\
\text { permissiva de interrupção de gravidez entre as suas excludentes de antijuridicidade. }\end{array}$ \\
\hline & $\begin{array}{l}\text { Mozarildo Cavalcanti } \\
\quad \text { (PTB/RR) }\end{array}$ & $\begin{array}{l}\text { PLS 50/2011 - altera Decreto-Lei } 2.848 \text { (1940) para dispor } \\
\text { que não se pune o aborto no caso de anencefalia fetal, se precedido } \\
\text { de consentimento da gestante ou de seu representante legal. }\end{array}$ \\
\hline & $\begin{array}{l}\text { José Sarney } \\
\text { (MDB/AP) }\end{array}$ & $\begin{array}{l}\text { PLS 236/2012 - reforma do Código Penal Brasileiro; altera o texto do artigo 128, } \\
\text { adicionando casos em que o aborto não é considerado crime. }\end{array}$ \\
\hline & $\begin{array}{l}\text { Programa } \\
\text { e-Cidadania }\end{array}$ & $\begin{array}{l}\text { SUG 15/2014 - regular a interrupção voluntária da gravidez dentro das doze primeiras } \\
\text { semanas de gestação pelo Sistema Único de Saúde. }\end{array}$ \\
\hline \multirow{8}{*}{ 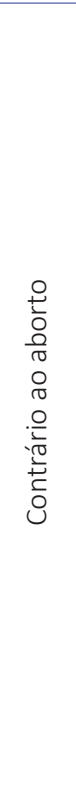 } & $\begin{array}{l}\text { Maria do Carmo } \\
\text { Alves (DEM/SE) }\end{array}$ & $\begin{array}{l}\text { PLS 287/2012 - acrescenta adendos ao artigo } 128 \text { do Decreto-Lei } 2.848 \text { (1940) } \\
\text { para dispor sobre o crime de interrupção da gravidez em caso de anencefalia. }\end{array}$ \\
\hline & \multirow{2}{*}{$\begin{array}{l}\text { Magno Malta } \\
\qquad(P R / E S)\end{array}$} & $\begin{array}{l}\text { RDH 18/2013 - requer a realização de audiência pública para debater decisão do } \\
\text { Conselho Federal de Medicina de praticar aborto com doze semanas de gravidez. }\end{array}$ \\
\hline & & $\begin{array}{l}\text { PLS 46/2017 - altera o Decreto-Lei } 2.848 \text { (1940) para criminalizar } \\
\text { a prática do aborto em qualquer fase da gestação. }\end{array}$ \\
\hline & \multirow[t]{2}{*}{$\begin{array}{l}\text { Pastor Valadares } \\
\text { (PDT/RO) }\end{array}$} & $\begin{array}{l}\text { PLS 460/2016 - altera o Decreto-Lei } 2.848 \text { (1940) para criminalizar o induzimento e a } \\
\text { instigação ao aborto e o anúncio de meio abortivo; exigir o exame de corpo de delito e } \\
\text { a prévia comunicação à autoridade policial para a não punição do aborto resultante de } \\
\text { estupro; modificar a Lei } 12.845 \text { (2013) para aperfeiçoar a redação dos artigos } 1 \text { o a 3‥ }\end{array}$ \\
\hline & & $\begin{array}{l}\text { PLS 461/2016 - altera o Decreto-Lei 2.848/1940 para criminalizar } \\
\text { a prática do aborto em qualquer estágio da gestação. }\end{array}$ \\
\hline & \multirow{2}{*}{$\begin{array}{l}\text { Eduardo Girão } \\
\text { (PODEMOS/CE) }\end{array}$} & $\begin{array}{l}\text { PL 556/2019 - elevar a pena do crime de aborto provocado por terceiro, com o } \\
\text { consentimento da gestante, e criar causa de aumento de pena. }\end{array}$ \\
\hline & & $\begin{array}{l}\text { PL 848/2019 - divulgação de informações de caráter educativo e preventivo que } \\
\text { possam contribuir para a redução da incidência da gravidez na adolescência. }\end{array}$ \\
\hline & $\begin{array}{l}\text { Flávio Arns } \\
\text { (REDE/PR) }\end{array}$ & $\begin{array}{l}\text { PL 2574/2019 - criminaliza o aborto provocado } \\
\text { que seja motivado pela má formação fetal. }\end{array}$ \\
\hline \multirow{3}{*}{ 일 } & \multirow{2}{*}{$\begin{array}{l}\text { Darci Ribeiro } \\
\text { (PDT/RJ) }\end{array}$} & RQS 71/1991 - solicita informações sobre o aborto ao Ministro da Justiça. \\
\hline & & RQS 75/1991 - solicita informações sobre o aborto ao Ministro da Saúde. \\
\hline & $\begin{array}{l}\text { Nelson Carneiro } \\
\text { (sem partido/RJ) }\end{array}$ & $\begin{array}{l}\text { RQS 668/1991 - requer transcrição nos anais do artigo do Dr. Hélio Aguinaga intitulado } \\
\text { 'Aborto fora do útero', publicado no jornal O Globo em 29/09/1991. }\end{array}$ \\
\hline
\end{tabular}


Continuação

\begin{tabular}{|c|c|c|}
\hline Tom & Autoria & Proposição e ementa \\
\hline \multirow{12}{*}{ 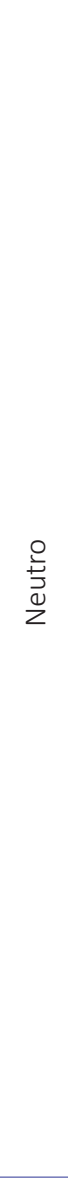 } & \multirow{2}{*}{$\begin{array}{l}\text { Expedito Júnior } \\
\qquad(\mathrm{PR} / \mathrm{RO})\end{array}$} & PLS 48/2008 - dispõe sobre a interrupção do estágio da estudante grávida. \\
\hline & & $\begin{array}{l}\text { PLS 54/2008 - altera o Regimento Interno para prever a concessão de } 30 \text { dias de } \\
\text { repouso remunerado à senadora gestante, em caso de natimorto ou de abortamento; } \\
\text { de cinco dias ao senador cujo cônjuge ou companheira se encontre na referida situação. }\end{array}$ \\
\hline & $\begin{array}{l}\text { Magno Malta } \\
\quad(P R / E S)\end{array}$ & $\begin{array}{l}\text { RDH 24/2015 - requer realização de audiência(s) } \\
\text { pública(s) para debater a SUG 15/2014. }\end{array}$ \\
\hline & Paulo Paim(PT/RS) & RDH 36/2015 - requer audiência pública para debater a SUG 15/2014. \\
\hline & $\begin{array}{l}\text { Regina Souza } \\
\text { (PT/PI) }\end{array}$ & $\begin{array}{l}\text { RDH 33/2015 - requer audiência pública para debater o Relatório da Anistia } \\
\text { Internacional que revela preocupação com violência, abortos e impunidade. }\end{array}$ \\
\hline & $\begin{array}{l}\text { Magno Malta (PR/ES) } \\
\text { e outros }\end{array}$ & $\begin{array}{l}\text { RDH 68/2018 - requer a realização de audiência pública para discutir a ADPF 442, } \\
\text { em trâmite no STF, sobre a descriminalização do aborto até as primeiras doze semanas. }\end{array}$ \\
\hline & $\begin{array}{l}\text { Maria do Carmo } \\
\text { Alves (DEM/SE) }\end{array}$ & $\begin{array}{l}\text { PLS 291/2018 - altera a Lei no 9.263/1996 (planejamento familiar) } \\
\text { para revogar a vedação da esterilização cirúrgica durante parto ou aborto, } \\
\text { e a exigência do consentimento expresso de ambos os cônjuges. }\end{array}$ \\
\hline & $\begin{array}{l}\text { Randolfe Rodrigues } \\
\qquad \text { (REDE/AP) }\end{array}$ & $\begin{array}{l}\text { PLS 107/2018 - altera a Lei no 9.263/1996, com o objetivo de facilitar } \\
\text { o acesso a procedimentos de laqueaduras e vasectomias. }\end{array}$ \\
\hline & $\begin{array}{l}\text { Comissão de } \\
\text { Assuntos Sociais }\end{array}$ & $\begin{array}{l}\text { RQS } 1067 / 2019 \text { - consulte-se o STF quanto a processo que diga respeito } \\
\text { à hipótese da prática do aborto por gestantes infectadas pelo vírus Zica. }\end{array}$ \\
\hline & $\begin{array}{l}\text { Flávio Arns } \\
\text { (REDE-PR) }\end{array}$ & $\begin{array}{l}\text { RQS 44/2019 - o mesmo requerimento } \\
\text { da RQS 1067/2019. }\end{array}$ \\
\hline & $\begin{array}{l}\text { Eduardo Girão } \\
\text { (PODEMOS/CE) }\end{array}$ & $\begin{array}{l}\text { RQS 28/2019 - requer aprovação de seminário para debater de } \\
\text { forma interdisciplinar questões que envolvem o Zica vírus e a microcefalia. }\end{array}$ \\
\hline & $\begin{array}{l}\text { Humberto Costa } \\
\qquad \text { (PT/PE) }\end{array}$ & $\begin{array}{c}\text { RQS 1706/2020 - requer informações ao Ministro da Saúde s } \\
\text { obre o paradigma dos direitos sexuais e reprodutivos. } \\
\text { RQS 1316/2020 - requer informações sobre oferta de ações e serviços } \\
\text { de saúde sexual e reprodutiva durante a pandemia de COVID-19. }\end{array}$ \\
\hline
\end{tabular}

Fonte: Elaborado pelos autores.

O julgamento do STF sobre a ADPF 54 (STF, 2013) - situação de anencefalia fetal - foi impactante para os grupos de interesses externos e internos ao Congresso, pois, sinalizou, pela primeira vez, uma mudança no fórum de política. A partir de então, os debates no Senado se intensificaram, ocorrendo realização de audiências públicas e o ingresso de projetos mais restritivos ao aborto, o que indica uma maior preocupação em assegurar o posicionamento do aborto como crime diante de sugestões para a sua descriminalização.

Um destaque foi a Sugestão SUG 15 (2014), originada no e-Cidadania com 20 mil inscritos, que teve como proposta regular o aborto voluntário dentro das 12 primeiras semanas de gestação. Ela foi discutida em cinco audiências públicas, que foram solicitadas para promover ampla discussão com diversos atores. A Consulta Pública da SUG 15/2014, disponível no Senado, recebeu 423.403 votos a favor e 381.116 contra, mas, em contrapartida, 34 câmaras de vereadores e a Assembleia Legislativa de Goiás encaminharam moções de repúdio contra a descriminalização do aborto. Depois dessas audiências, projetos mais restritivos ao aborto foram apresentados. Ao final de 2018 a sugestão foi arquivada.

Dentre os projetos de lei que constam do Quadro 2, oito estão em trâmite: PLS 48/2008, remetido à Câmara dos Deputados; PLS 460 e PLS 461, de 2016, prontos para pauta na Comissão de Constituição e Justiça e Cidadania (CCJC); PLS 107/2018, que trata da facilitação de acesso a procedimentos de laqueaduras e vasectomias; PLS 236/2012, projeto que trata da reforma do Código Penal, ao qual a PLS 460/2016 foi apensada; PLS 225/2019, que sugere elevar a pena do crime de aborto provocado por terceiro; PLS 848/2019, sobre divulgações de informações de caráter educativo relativas à redução de incidência de gravidez na adolescência e sobre os riscos da prática de aborto; e PLS 2574/2019, o qual criminaliza o aborto provocado que seja motivado pela má formação fetal. 
O Requerimento RDH 68, de Magno Malta (Senado Federal, 2018), para a realização de Audiência Pública sobre a ADPF 442 (STF, 2017), acabou sendo arquivado. Nele, o senador havia proposto a discussão do conteúdo da arguição, a descriminalização do aborto até a décima segunda semana de gestação, bem como o "ativismo judicial do Supremo Tribunal" (Senado Federal, 2018, p. 3). Impacta ainda sobre a questão do aborto, embora não mencione a palavra, a PEC 29/2015 (Senado Federal, 2015, p. 1), a qual propõe acrescentar ao art. 50 da Constituição "[...] a explicitação inequívoca da inviolabilidade do direito à vida, desde a concepção", apresentada por Magno Malta (PR-ES) e assinada por mais 28 senadores. A PEC 29 (2015), arquivada ao final de 2018, foi desarquivada em fevereiro de 2019 pelo senador Eduardo Girão (Podemos/CE). Como noticiado pelo Senado Federal (2019, p. 2), "[...] diversos senadores apoiaram o desarquivamento da PEC para que o Senado e a Câmara possam debater e analisar o tema para não deixar que o Supremo Tribunal Federal (STF) invada competências do Congresso Nacional".

\section{Análise dos pronunciamentos no Senado Federal}

O Gráfico 2 apresenta o número de pronunciamentos dos senadores por ano e conforme o tom. Ao total são 72 pronunciamentos de tom neutro ( $24,4 \%$ do total), 71 pronunciamentos favoráveis $(24,1 \%)$ e, por fim, 152 pronunciamentos de tom contrário, equivalentes a $51,5 \%$ do total.

O número de pronunciamentos favoráveis ao aborto apresenta-se geralmente em um número menor ao de discursos contrários, salvo alguns períodos em que ocorreu o oposto. É o que acontece entre os anos de 2001 e 2004, período em que o número de pronunciamentos favoráveis ultrapassa o número contrário. Isso acontece novamente apenas nos anos de 2006 e de 2016. De 2017 em diante, predominam pronunciamentos contrários ao aborto, com um número maior no ano eleitoral de 2018 e oscilando a partir de então.

Durante o mandato de Fernando Henrique Cardoso, os pronunciamentos contrários superam o número de discursos favoráveis ao aborto. Em 2001, há uma mudança no tom dos pronunciamentos, passando a haver mais posições favoráveis e neutras. Em 2003, curiosamente, após o ano eleitoral em que Luiz Inácio Lula da Silva foi eleito presidente, não há pronunciamentos sobre o aborto.

\section{Gráfico 2}

Número e tom de pronunciamentos dos senadores por ano

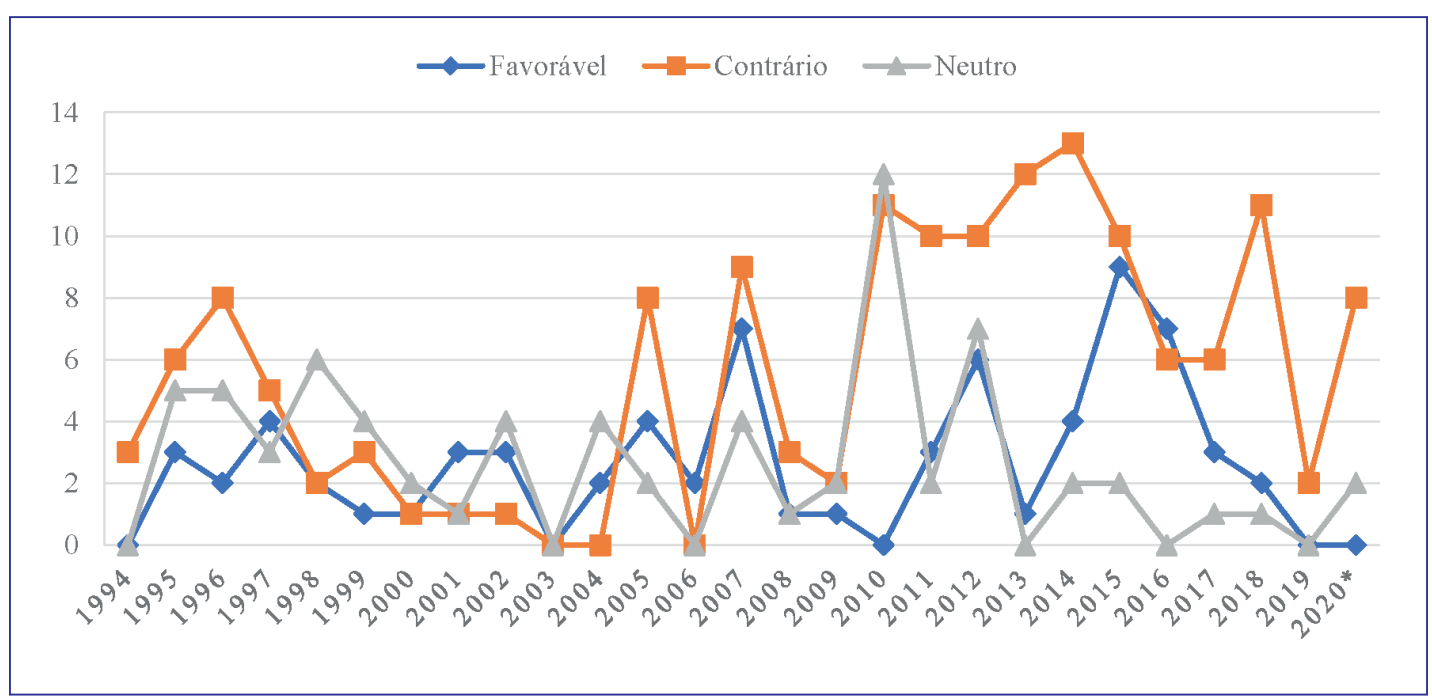

Nota: * contempla as proposições iniciadas até 15 outubro de 2020.

Fonte: Elaborado pelos autores.

Em 2004, reinicia-se o debate em tom mais favorável. Em 2005, no entanto, há um aumento do número de posições contrárias, dando início a um período de oscilações no número de pronunciamentos. Em 2010, o aborto ganha espaço na agenda da mídia (Barreras, 2013; Mantovani, 2014) e mais atenção do Senado, especialmente durante o segundo turno das eleições, com pronunciamentos predominantemente neutros. 
A partir de 2011, durante o primeiro mandato de Dilma Rousseff, os pronunciamentos contrários se sobressaem, especialmente pela participação contínua de Magno Malta (PR/ES). As posições favoráveis vêm principalmente de Vanessa Grazziotin (PCdoB/AM), Marta Suplicy (PMDB/SP) e Humberto Costa (PT/PE).

Os anos eleitorais geralmente concentram discursos contrários, como ocorre em 2010, 2014 e 2018. Isso pode estar relacionado à polêmica envolvendo o debate dos presidenciáveis e a influência que a mídia direciona à questão do aborto, especialmente no segundo turno das eleições de 2010 (Barreras, 2013; Mantovani, 2014). Entre 2013 e 2016, há um crescimento no número de posicionamentos favoráveis e decréscimo no número de contrários, bem como uma redução de neutros. A partir de 2017 predominam posicionamentos contrários. Após o resultado das eleições presidenciais de 2018, o posicionamento contrário ao aborto é acompanhado pela preferência à estabilidade nesta questão, como exposto pelo presidente Jair Bolsonaro.

Dos 295 pronunciamentos, 24 são de participantes da Comissão de Direitos Humanos e Legislação Participativa (CDH), entre eles seu atual presidente, Paulo Paim (PT/RS). Considerando as Frentes Parlamentares Mistas (FPM), cinco pronunciamentos são de membros da FPM em Defesa da Vida e Contra o Aborto, 15 são da FPM de Direitos Humanos da Mulher. Os pronunciamentos de Magno Malta correspondem à sua participação na FPM da Família e Apoio à Vida e Gestantes (54a legislatura). Em média, tem-se três pronunciamentos por senador, entretanto, alguns tiveram uma quantidade de falas muito acima deste número, o que sugere um engajamento maior com a questão, seja a favor da descriminalização ou contra o aborto. Do total de 54 pronunciamentos de mulheres, $28(51,8 \%)$ foram favoráveis ao aborto, seguidos de $21(38,9 \%)$ neutros e cinco $(9,3 \%)$ contrários. Do total de 241 pronunciamentos masculinos, houve 43 (17,8\%) favoráveis, 51 (21,2\%) neutros e 147 (61,0\%) pronunciamentos contrários.

Como um todo, o menor número de pronunciamentos femininos pode estar relacionado ao número de mulheres no Senado, quando se observa que, entre 1988 e 2018, 17 senadoras, no máximo, ingressaram no Senado na mesma legislatura.

Considerando o tom dos pronunciamentos por partido político, verificou-se que os partidos não possuem uma posição homogênea a respeito do aborto. 0 Gráfico 3 apresenta aqueles com ao menos quatro pronunciamentos no período e o respectivo tom dos argumentos.

Pode-se observar que os pronunciamentos de senadores dos partidos PCdoB, PT e PTB seguem um tom predominantemente favorável ao aborto, a exemplo dos senadores: Paulo Paim (PT/RS, $n=5$ pronunciamentos), Marta Suplicy (PT, PMDB/SP, $n=8$ ) e Vanessa Grazziotin (PCdoB/AM, $n=8$ ). Gilvam Borges (PMDB/AP, $n=11$ ) assume posição favorável, e PMDB e PSDB apresentam-se como legendas de posição mista.

\section{Gráfico 3}

Percentual do tom dos pronunciamentos por partido político

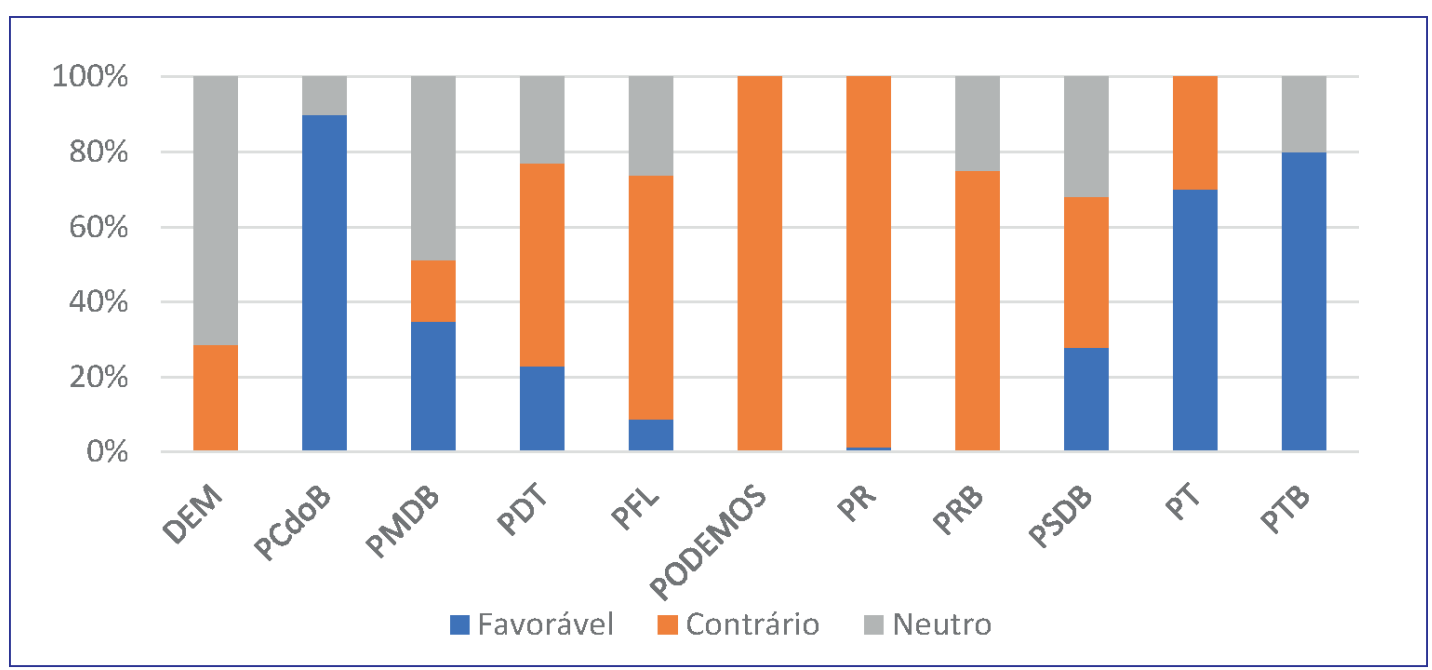

Fonte: Elaborado pelos autores. 
Mais recentemente, predominam tons contrários nos pronunciamentos de senadores do PDT, PFL/DEM, Podemos, PR e PRB: Odacir Soares (PFL/DEM/RO, $n=11$ pronunciamentos), especialmente nos anos 90; Magno Malta (PR/ES, $n=67$ pronunciamentos) e Eduardo Girão (Podemos/CE, n=11 pronunciamentos).

As políticas de saúde da mulher, do planejamento familiar e do combate à violência contra as mulheres não são argumentos exclusivos de posições favoráveis, contrárias ou neutras. Alguns pronunciamentos ocorrem em momentos de definição de tais políticas e relembram acontecimentos significativos, tais como a IV Conferência Mundial sobre a Mulher, em Pequim, a Conferência do Cairo, o Programa de Atenção Integral à Saúde da Mulher (PAISM) e o dia 28 de maio, Dia Internacional de Ação pela Saúde da Mulher.

O Quadro 3 apresenta argumentos de pronunciamentos que ilustram o tom da imagem política conforme a ordem cronológica em que aparecem.

\section{Quadro 3}

Argumentos de pronunciamentos favoráveis, contrários e neutros

\begin{tabular}{|c|l|}
\hline Tom & \multicolumn{1}{c|}{$\begin{array}{c}\text { Argumentos de senadores em ordem cronológica } \\
\text { Favorável }\end{array}$} \\
\hline \multirow{5}{*}{ Contrário } & $\begin{array}{l}\text { A mulher tem que ter o direito garantido à interrupção da gravidez [...] quantas delas morrem, Sr. Presidente, } \\
\text { A vulnerabilidade se acentua na saúde. Quinhentas mil mulheres morrem anualmente durante a gravidez e o } \\
\text { parto, no País. [...] Duzentas mil morrem durante o ano, em consequência do aborto inseguro (Grazziotin, 2012). }\end{array}$ \\
\hline $\begin{array}{c}\text { Da mesma forma, ao opor-me à legalização do aborto [...] na verdade estava concedendo ênfase ainda maior } \\
\text { à defesa dos fracos e inocentes (Soares, 1996). } \\
\text { A vida começa com a concepção, e o aborto, na concepção, já é um brutal assassinato (Malta, 2013). } \\
\text { Não é só a vida do bebê que é destruída-o que já é muita coisa-, com o aborto; a saúde da mulher, segundo } \\
\text { comprovam a ciência e as estatísticas sociais do Brasil e do mundo inteiro, fica comprometida emocional, } \\
\text { psicológica e até fisicamente (Girão, 2019). }\end{array}$ \\
$\begin{array}{l}\text { Nesse programa, o mais importante é a informação. Então, temos que levar a todas as mulheres do nosso } \\
\text { país e a todas as moças de tenra idade - desde a puberdade - os ensinamentos necessários para que não } \\
\text { haja a gravidez indesejada, o aborto provocado e, conforme V. Ex frisou, o grande índice de mulheres que } \\
\text { são mutiladas - quando não mortas - nessas clínicas clandestinas, já chegando ao hospital com várias } \\
\text { sequelas (Patrocínio, 1998). }\end{array}$ \\
\hline Neutro
\end{tabular}

Fonte: Elaborado pelos autores.

Dados estatísticos sobre mortalidade materna e abortos são constantemente empregados para o convencimento por senadores favoráveis ao aborto, nos casos previstos na legislação. Entretanto, a confiabilidade de tais dados é uma dificuldade conhecida pelos atores interessados, que, para defender sua posição, utilizam-se de estimativas questionadas pelos opositores. Outra estratégia retórica em pronunciamentos favoráveis ao aborto é a preferência pelo termo "interrupção da gravidez". Percebe-se que a estratégia de informação, central ao processo de políticas públicas (Baumgartner \& Jones, 2015), é usada tanto no debate quanto no questionamento das posições contrárias.

Menções à igreja e às crenças religiosas são utilizadas em argumentos favoráveis e contrários, uns como crítica à influência religiosa no debate da questão e outros como suporte à posição contrária ao aborto, por representar os valores de parte da população.

Na perspectiva contrária ao aborto, os argumentos usados são: a defesa da vida desde a concepção, o entendimento do aborto como assassinato de inocentes, além de argumentos de cunho religioso e menções ao Papa João Paulo II. Tons contrários mais brandos admitem os casos não puníveis previstos no Código Penal e na decisão da ADPF 54 (STF, 2013). Os pronunciamentos classificados como neutros, por sua vez, procuram construir uma imagem da política que articula diferentes perspectiva da questão, como ao relacionar o problema da mortalidade materna e as consequências do aborto.

Nesse contexto de proposições legislativas e de pronunciamentos no Senado, emergiram pedidos para a realização de audiências públicas, buscando um maior debate com a sociedade, o que permitiu também abordar as preferências de atores externos ao Senado. 


\section{Audiências públicas como eventos focalizadores}

Das seis audiências públicas, cinco discutem a SUG 15 (2014) e uma aborda o Relatório de Anistia Internacional. Os debates apresentaram posições opostas e polêmicas, a favor da descriminalização do aborto e do direito decisório da mulher, ou contra o aborto e em defesa da vida desde a concepção.

Além da presença de senadores e alguns deputados federais, foi encontrada uma significativa participação de acadêmicos, especialmente da área médica e de direito, ativistas pró-vida, ativistas feministas, fundadoras de organizações que prestam suporte às gestantes, representantes de instituições nacionais com interesse na questão e representantes religiosos. 0 Quadro 4 enumera os participantes externos e internos, com respectivas organizações, conforme tom favorável ou contrário ao aborto.

Os participantes das audiências abordam temas como direitos sexuais e reprodutivos, saúde da mulher, mortalidade materna, gestação e direito à vida desde a concepção, recomendações da Organização Mundial da Saúde (OMS) e do Conselho Federal de Medicina (CFM) e citam pesquisa em parceria entre Ministério da Saúde e UnB (Diniz \& Medeiros, 2010), considerada como fonte de informação ao debate. Débora Diniz participa de uma audiência do Senado e tem atuado na busca por mudanças em participações no STF e também da discussão do ADPF 54 (STF, 2013) do STF. Seu estudo em bioética também foi citado em pronunciamentos em 2001 por dois senadores.

\section{Quadro 4}

Participantes de audiências públicas na comissão de direitos humanos, por tom favorável ou contrário ao aborto

\begin{tabular}{|c|c|c|}
\hline Tom & Tipo & Participantes e Organizações \\
\hline 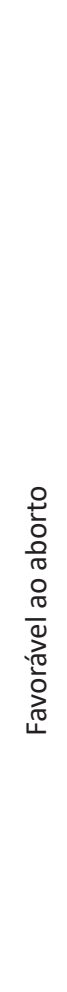 & 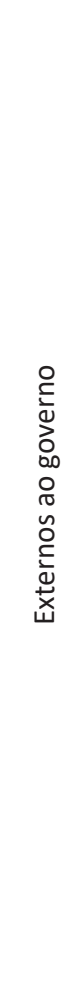 & $\begin{array}{l}\text { 1. Ana Maria Costa, Centro Brasileiro de Estudos da Saúde (CEBES). } \\
\text { 2. Beatriz Galli, Com. Latino-Americano e Caribe Defesa Direitos da Mulher (CLADEM). } \\
\text { 3. Débora Diniz, professora, Instituto de Bioética, Direitos Humanos e Gênero - ANIS/UnB. } \\
\text { 4. Eloísa Machado Almeida, advogada e ativista. } \\
\text { 5. Henrique Batista e Silva, secretário geral do Conselho Federal de Medicina (CFM). } \\
\text { 6. Ilka Teodoro, Coord. da Comissão da Mulher na Ordem dos Advogados do Brasil (OAB). } \\
\text { 7. Jolúzia Batista, socióloga, Frente Nacional contra a Criminalização das Mulheres e pela } \\
\text { 8. José Eustáquio Diniz Alves, Escola Nacional de Ciências Estatísticas - ENCE/IBGE. } \\
\text { 9. Leila Linhares, advogada e ativista. } \\
\text { 10. Letícia Bonifaz, senadora mexicana e professora. } \\
\text { 11. Márcia Tiburi, Professora da Universidade Presbiteriana Mackenzie. } \\
\text { 12. Maria José Rosado Nunes, Católicas pelo Direito de Decidir. } \\
\text { 13. Maria Teresa Blandón, ativista feminista da Nicarágua. } \\
\text { 14. Melânia Amorim, médica obstetra. } \\
\text { 15. Olímpio Barbosa Morais Filho, Federação Brasileira de Ginecologia e Obstetrícia. } \\
\text { 16. Rosângela Aparecida Talib, Movimento Católicas pelo Direito de Decidir. } \\
\text { 17. Sandra Valongueiro, pesquisadora da Universidade Federal de Pernambuco. } \\
\text { 18. Sônia Correa, Associação Brasileira Interdisciplinar de AIDS. } \\
\text { 19. Tatiana Lionço, psicóloga, Movimento Estratégico pelo Estado Laico. } \\
\text { 20. Thomaz Gollop, médico, Grupo de Estudos do Aborto (GEA). }\end{array}$ \\
\hline & 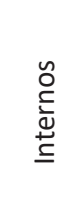 & $\begin{array}{l}\text { 21. Jean Wyllys, Deputado Federal (PSOL/RJ). } \\
\text { 22. Maria do Socorro Souza, Conselho Nacional da Saúde (CNS). } \\
\text { 23. Maria Esther Albuquerque Vilela, Coordenadora Geral da Saúde da Mulher do Ministério da Saúde - } \\
\text { duas participações. } \\
\text { 24. Rurany Ester Silva, Secretaria de Políticas para Mulheres. }\end{array}$ \\
\hline
\end{tabular}




\begin{tabular}{|c|c|c|}
\hline Tom & Tipo & Participantes e Organizações \\
\hline \multirow[t]{2}{*}{ 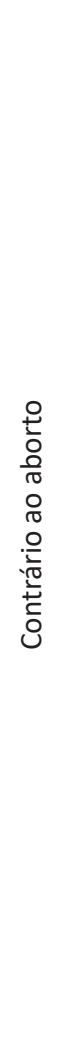 } & 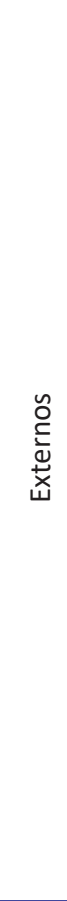 & $\begin{array}{l}\text { 1. Adelice Leite Godoy D’Ávila, Movimento Pró-Vida de Campinas (SP). } \\
\text { 2. Eliane Oliveira, médica e professora, Universidade Federal do Ceará. } \\
\text { 3. Elizabeth Kipman Teixeira, médica. } \\
\text { 4. Cláudio Fonteles, ex-procurador geral da República. } \\
\text { 5. David Kyle, cineasta, produtor do filme "Blood Money". } \\
\text { 6. Dóris Hipólito, Fundadora das Casas de Âmparo às Gestantes do RJ. } \\
\text { 7. Fernanda Takitani, professora, Observatório Interamericano de Biopolítica. } \\
\text { 8. Heloísa Helena, vereadora (PSOL/AL), ex-senadora. } \\
\text { 9. Isabela Mantovani, especialista em saúde coletiva. } \\
\text { 10. Lenise Garcia, professora do Instituto de Biologia da Universidade de Brasília- UnB. e Presidente } \\
\text { 11. Nazareno Vasconcelos Feitosa, Movimento Brasil Movida, DF. } \\
\text { 12. Padre Berardo Graz, representante em defesa da vida, Regional Sul da CNBB. } \\
\text { 13. Padre Paulo Ricardo. } \\
\text { 14. Padre Pedro Sepien, Diretor Nacional Pró-Vida. } \\
\text { 15. Rosemeire Santiago, diretora do Centro de Reestruturação para a Vida. } \\
\text { 16. Sara Winter, ativista pró-vida, SP. } \\
\text { 17. Stela Barbas, doutora em direito e professora, Portugal. } \\
\text { 18. Viviane Petinelli e Silva, Instituto Políticas Governamentais do Brasil. }\end{array}$ \\
\hline & 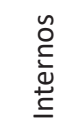 & $\begin{array}{l}\text { 19. Damares Alves, funcionária do Senado, Assessora da Frente Parlamentar da Família. } \\
\text { 20. Luiz Bassuma (PT/BA), Deputado Federal, autor do projeto estatuto do nascituro. } \\
\text { 21. Marco Feliciano, Deputado Federal (PSC-SP) - duas participações. }\end{array}$ \\
\hline
\end{tabular}

Fonte: Elaborado pelos autores.

Advogadas de posicionamento favorável enfatizam que em outros países a Suprema Corte tem assumido essa questão, sugerindo esse fórum para que se busquem mudanças na política. "A ativista feminista Leila Linhares, também advogada, observou que as cortes constitucionais internacionais, ao tratar do aborto, estão tendendo à regulamentação da prática dentro de doze semanas" (Senado Federal, 2016, p. 5).

A ADPF 442 (STF, 2017), encaminhada pelo PSOL para o STF, ilustra uma tentativa de buscar mudança para a descriminalização do aborto via fórum do STF. Ao aplicar a teoria do equilíbrio pontuado para decisões da Suprema Corte, Gillman (2002) descreve essa estratégia como "entrenchment", em que partidos políticos usam a Suprema Corte para avançar suas agendas ao remover o debate político da arena eleitoral (Gillman, 2002; Robinson, 2013). Contudo, como discutido pelos senadores, a competência do STF não pode se sobrepor ao papel do legislativo ou ainda adicionar conteúdo externo ao previsto na Constituição, o que seria ativismo judicial, segundo os senadores. Assim, no Senado a discussão tende a manter a imagem da questão do aborto conforme a preferência da maioria observada no tom contrário predominante, mantendo o monopólio de política, em proposições legislativas e pronunciamentos, ao passo que as audiências públicas foram eventos focalizadores que desafiaram a imagem predominante da questão.

Os pronunciamentos também revelaram novas imagens para a questão, enquadrando o aborto não apenas como crime (problema), mas como direito (solução). Essa nova imagem tem ganhado mais espaço de discussão no contexto do STF, a partir especialmente de 2004, com a ADPF 54 (STF, 2013), encaminhada por ator externo ao governo e a ADPF 442 (STF, 2017), encaminhada por partido político. Diante disso, os senadores questionam a atuação do STF como fórum para deliberações sobre a questão, uma vez que, ao adicionar a mudança na legislação sobre o aborto na ADPF 54 (STF, 2013), pode se tornar uma via para mudanças mais rápidas, paralelamente ao Congresso Nacional, por não depender dos trâmites legislativos próprios do Congresso e não ter como competência a representação da população. O Senado termina o período em análise tendendo para a estabilidade e revelando pequenas mudanças incrementais. Permanecem em aberto as deliberações sobre o projeto de reforma do Código Penal (PLS 236, 2012), da PEC 29 (2015), retomada em 2019, bem como o julgamento da ADPF 442 pelo 
STF (2017). Isso se insere em um contexto político em que o Presidente e o Ministro da Saúde são atores-chave, na medida em que lidam com as controvérsias de diferentes posicionamentos e implementam políticas com base em suas preferências.

Podemos concluir elencando os principais fatores que promoveram mudanças na atenção e na imagem da política relacionada ao aborto, no contexto do Senado, dispostos no Quadro 5:

Quadro 5

Fatores que interferem na agenda do aborto no senado federal - 1988 a out. 2020

\begin{tabular}{|c|c|}
\hline \multirow{6}{*}{$\begin{array}{l}\text { Agenda do aborto } \\
\text { no Senado Federal } \\
1988 \text { a out. } 2020\end{array}$} & Fatores \\
\hline & 1. Promoção de novas imagens da política. \\
\hline & 2. Introdução/adição de novos fóruns de política (o STF). \\
\hline & $\begin{array}{l}\text { 3. Atuação de atores-chave, como o Presidente e ministros da saúde, mas também de } \\
\text { atores externos ao governo. }\end{array}$ \\
\hline & $\begin{array}{l}\text { 4. Fatores novos que oportunizam mudanças incrementais - anencefalia, Zika vírus, } \\
\text { microcefalia, pandemia, casos traumáticos noticiados. }\end{array}$ \\
\hline & 5. Fator internacional, o aborto em outros países. \\
\hline
\end{tabular}

Fonte: Elaborado pelos autores.

Este primeiro estudo das dinâmicas da agenda da política de moralidade do aborto está circunscrito ao Senado Federal. Outros elementos relacionados às dinâmicas da agenda do aborto podem ser abrangidos com o estudo de outros fóruns de política, bem como a opinião pública e os meios de comunicação.

\section{CONCLUSÃo}

O objetivo desse trabalho foi analisar as dinâmicas da agenda da política de moralidade do aborto no Senado Federal, entre 1988 e outubro de 2020. Foi possível identificar posições favoráveis e contrárias ao aborto, por meio da análise de pronunciamentos e projetos de senadores, da posição por partidos e dos argumentos relacionados à imagem da política. Também foi possível identificar o perfil dos participantes externos e as organizações que eles representam nos debates em audiências públicas. Há novas percepções ou imagens da política em jogo, atores externos mobilizaram-se durante os eventos focalizadores das audiências públicas ocorridas no Senado. Paralelamente, o STF surge como fórum decisório alternativo, ao adicionar mudanças por meio da ADPF 54 (2013) na legislação do aborto (caso da anencefalia), no qual ainda os ministros deliberarão sobre a ADPF 442 (STF, 2017), encaminhada pelo PSOL.

A análise permite descrever um aumento no número de pronunciamentos na última década, havendo uma maior concentração durante os anos eleitorais de 2010, 2014 e 2018, por ser um tema recorrente em debates para eleições presidenciais. Novas propostas legislativas e o incremento na quantidade de pronunciamentos antecedem um período de várias audiências públicas. A preocupação com a saúde e os direitos das mulheres sustentam os argumentos que procuram descriminalizar o aborto, e posições contrárias defendem a vida e veem o aborto como uma causa da mortalidade materna e fetal.

Os argumentos dos senadores não contemplam meios de ação do Estado no caso de liberação, tais como esforços educacionais e campanhas de mídia, apenas citam a necessidade. Apesar disso, propõem-se mudanças incrementais, como de caráter informativo-preventivo; e de uma forma geral, tramitam projetos de lei de desdobramentos opostos, alguns pela descriminalização, como a proposta de reforma do Código Penal, e outros pelo aumento da punição em casos específicos. No período analisado prevaleceu estabilidade no Senado, com mudanças substanciais acontecendo na deliberação da ADPF 54 pelo STF (2013).

A análise neste estudo, restringe-se, assim, ao Senado. Futuras pesquisas podem analisar pronunciamentos e proposições legislativas da Câmara dos Deputados, bem como abordar a discussão no âmbito do STF. Cabe ainda analisar a agenda da mídia, para o mesmo período, sob a perspectiva de Baumgartner e Jones (1993), e discutir o papel do STF e a questão do ativismo judicial, para complementar o entendimento do que tem contribuído para sua estabilidade ou mudança. A compreensão das organizações que sustentam a participação dos empreendedores políticos permitiria conhecer novos elementos que interferem na política de moralidade do aborto, como a influência da agenda de organismos internacionais e de empreendedores de políticas estrangeiros. 


\section{AGRADECIMENTOS}

Agradecemos à Universidade do Estado de Santa Catarina (UDESC) pelo apoio oferecido por meio de bolsa de monitoria, no âmbito do Programa PROMOP, durante o primeiro ano de doutorado da autora Maria Clara Figueiredo Dalla Costa Ames. Agradecemos também à Coordenação de Aperfeiçoamento de Pessoal de Nível Superior (Capes), pelo apoio com uma Bolsa do Programa de Demanda Social Capes, para a autora Maria Clara Figueiredo Dalla Costa Ames, durante parte de seu doutorado, do qual resultou este artigo, entre outras publicações, inseridas nos trabalhos do grupo de pesquisa AdmEthics (ESAG/UDESC). 


\section{REFERÊNCIAS}

Anderson, J. E. (2003). Public Policymaking: an introduction (5a ed.). Boston, MA: Houghton Mifflin Company.

Anderson, S. E., Deleo, R. A., \& Taylor, K. (2019). Policy Entrepreneurs, Legislators, and Agenda Setting: Information and Influence. Policy Studies Journal, 48(3), 1-25.

Banchoff, T. (2011). Embryo politics: ethics and policy in atlantic democracies. Ithaca, NY: Cornell University Press.

Bardin, L. (2009). Análise de conteúdo. Lisboa, Portugal: Edições 70.

Barreras, S. E. O. B. (2013). O agendamento do aborto na campanha presidencial brasileira em 2010: reverberação e silenciamento estratégicos em imprensa, mídia sociais e candidatos (Tese de Doutorado). Universidade Federal do Rio Grande do Sul, Porto Alegre, RS.

Baumgartner, F. R., \& Jones, B. D. (1993). Agendas and instabilities in american politics. Chicago, IL: University of Chicago Press.

Baumgartner, F. R., \& Jones, B. D. (2015). The politics of information. Chicago, IL: University of Chicago Press.

Baumgartner, F. R., Jones, B. D., \& Wilkerson, J. (2011). The dynamics of policy change in comparative perspective. Comparative Political Studies, 44(8), 947-972.

Birkland, T. E. (2005). An introduction to the policy process (2a ed.). Armonk, NY: M. E. Sharpe.

Borges, G. (1996). Pronunciamento de Gilvam Borges de 26/02/1996. Recuperado de https://www25.senado.leg.br/web/atividade/ pronunciamentos/-/p/texto/182322

Calkin, S., \& Kaminska, M. E. (2020). Persistence and change in Morality Policy: the role of the Catholic Church in the Politics of Abortion in Ireland and Poland. Feminist Review, 124(1), 86-102.

Capella, A. C. N. (2016). Um estudo sobre o conceito de empreendedor de políticas públicas: Ideias, interesses e mudanças. Cadernos EBAPE.BR, 14(5), 486-505.

Capella, A. C. N. (2018). Formulação de políticas públicas. Brasília, DF: ENAP, 2018.

Chaqués-Bonafont, L., Palau, A. M., \& Baumgartner, F. R. (2015). Agenda Dynamics in Spain. Hampshire, UK: Palgrave Macmillan.

Dall'agnol, D., \& Tonetto, M. C. (2015). Morality and life: Kantian perspectives in Bioethics. Pisa, Italy: Edizioni ETS.

Decreto-Lei 2.848, de 7 de dezembro de 1940. (1940). Código Penal. Brasília, DF. Recuperado de http://www.planalto.gov.br/ccivil_03/ Decreto-lei/Del2848compilado.htm

Diniz D., \& Medeiros, M. (2010). Aborto no Brasil: uma pesquisa domiciliar com técnica de urna. Ciência e Saúde Coletiva, 15(1), 959-966.

Dodds, A. (2013). Comparative public policy. Basingstoke, UK: Palgrave MacMillan.

Dworkin, R. (2009). Domínio da vida: aborto, eutanásia e liberdades individuais (2a ed.). São Paulo, SP: Martins Fontes.
Engeli, I. (2009). The Challenge of Abortion and ART Policies in Europe. Comparative European Politics, 7(1), 56-74.

Engeli, I., Green-Pedersen, C., \& Larsen, L. T. (2012). Morality Politics in Western Europe: parties, agendas and policy choices. Hampshire, UK: Palgrave Macmillan.

Finnis, J. (2019). Unborn Human Life and Fundamental Rights: Concluding Reflections. In P. Zambrano \& W. Saunders (Eds.), Unborn Human Life and Fundamental Rights: Leading Constitutional Cases under Scrutiny (pp. 255-265). Berlin, Germany: Peter Lang.

Gillman, H. (2002). How political parties can use the courts to advance their agendas: Federal Courts in the United States, 1875-1891. American Political Science Review, 96(3), 511-524.

Girão, E. (2019, outubro 04). Pronunciamento de Eduardo Girão. Recuperado de https://www25.senado.leg.br/web/atividade/ pronunciamentos/-/p/texto/458223

Grazziotin, V. (2012, maio 21). Pronunciamento de Vanessa Grazziotin em 21/05/2012. Recuperado de https://www25.senado.leg.br/web/ atividade/pronunciamentos/-/p/texto/393068

Kingdon, J. W. (2003). Agendas, alternatives, and public policies (2a ed.). New York, NY: Longman.

Knill, C. (2013). The study of morality policy: analytical implications from a public policy perspective. Journal of European Public Policy, 20(3), 309-317.

Lei 9.263, de 12 de janeiro de 1996. (1996). Regula o § 70 do art. 226 da Constituição Federal, que trata do planejamento familiar, estabelece penalidades e dá outras providências. Brasília, DF. Recuperado de http://www.planalto.gov.br/ccivil_03/Leis/L9263.htm

Lei 12.845, de 1ㅇ de agosto de 2013. (2013). Dispõe sobre o atendimento obrigatório e integral de pessoas em situação de violência sexual. Brasília, DF. Recuperado de http://www.planalto.gov.br/ccivil_03/_ Ato2011-2014/2013/Lei/L12845.htm

Machado, M. R. A., \& Cook, R. J. (2018). Constitutionalizing abortion in Brazil. Revista de Investigações Constitucionais, 5(3), 185-231.

Malta, M. (2013, março 23). Pronunciamento de Magno Malta em 25/03/2013. Recuperado de https://www25.senado.leg.br/web/ atividade/pronunciamentos/-/p/texto/397940

Mantovani, D. M. (2014). Quem agenda a mídia: um estudo de agendasetting a partir da tematização do aborto nas eleições de 2010 (Tese de Doutorado). Universidade de Brasília, Brasília, DF.

Miguel, L. F., Biroli, F., \& Mariano, R. (2017). O direito ao aborto no debate legislativo brasileiro: a ofensiva conservadora na Câmara dos Deputados. Opinião Pública, 23(1), 230-260.

Mooney, C. Z. (2000). The decline of federalism and the rise of morality-policy conflict in the United States. Publius, 30(1), 171-188.

Mooney, C. Z. (2001). The public clash of private values: The politics of morality policy. New York, NY: Chatham House.

Munson, Z. W. (2018). Abortion politics. Medford, MA: Polity. 
Oliveira, A. A. S., Montenegro, S., \& Garrafa, V. (2005). Supremo Tribunal Federal do Brasil e o aborto do anencéfalo. Bioética, 13(1), 79-92.

Patrocínio, C. (1998). Pronunciamento de Carlos Patrocínio de 07/04/1998. Recuperado de https://www25.senado.leg.br/web/ atividade/pronunciamentos/-/p/texto/224084

Projeto de Lei da Câmara n. 18, de 2001. (2001). Dispõe sobre a obrigatoriedade de os servidores das Delegacias de Polícia informarem as vítimas de estupro sobre o direito de aborto legal. Brasília, DF. Recuperado de https://www25.senado.leg.br/web/atividade/ materias/-/materia/46746

Projeto de Lei do Senado n. 28, de 1997. (1997). Altera a Lei 9.263, de 12 de janeiro de 1996 (planejamento familiar) e dá outras providências. Brasília, DF. Recuperado de https://www25.senado. leg.br/web/atividade/materias/-/materia/24951

Projeto de Lei do Senado n. 46, de 2017. (2017). Altera o Decreto-Lei no 2.848 , de 7 de dezembro de 1940 - Código Penal, para criminalizar a prática do aborto em qualquer fase da gestação. Brasília, DF. Recuperado de https://www25.senado.leg.br/web/atividade/ materias/-/materia/128234

Projeto de Lei do Senado n. 48, de 2008. (2008). Dispõe sobre a interrupção do estágio da estudante grávida. Brasília, DF. Recuperado de https://www25.senado.leg.br/web/atividade/materias/-/ materia/84066

Projeto de Lei do Senado n. 50, de 2011. (2011). Insere inciso III ao art. 128 do Decreto-Lei n. 0 2.848, de 1940 para incluir os casos de anencefalia fetal. Brasília, DF. Recuperado de https://www25.senado. leg.br/web/atividade/materias/-/materia/99165

Projeto de Lei do Senado n. 78, de 1993. (1993). Disciplina a prática do aborto, altera o Decreto-lei 2.848, de 07 de dezembro de 1940 - Código Penal - e dá outras providências. Brasília, DF. Recuperado de https:// www25.senado.leg.br/web/atividade/materias/-/materia/26739

Projeto de Lei do Senado n. 107, de 2018. (2018). Altera a Lei no 9.263, de 12 de janeiro de 1996, que trata do planejamento familiar, com o objetivo de facilitar o acesso a procedimentos laqueaduras e vasectomias. Brasília, DF. Recuperado de https://www25.senado. leg.br/web/atividade/materias/-/materia/132552

Projeto de Lei do Senado n. 183, de 2004. (2004). Altera a redação do art. 128 do Decreto-Lei no 2.848, de 7 de dezembro de 1940 - Código Penal, para nele incluir o caso de aborto de feto anencéfalo. Brasília, DF. Recuperado de https://www25.senado.leg.br/web/atividade/ materias/-/materia/68457

Projeto de Lei do Senado n. 227, de 2004. (2004). Altera o art. 128 do Decreto-Lei no 2.848, de 7 de dezembro de 1940, Código Penal, para não punir a prática do aborto realizado por médico em caso de anencefalia fetal. Brasília, DF. Recuperado de https://www25.senado. leg.br/web/atividade/materias/-/materia/69514

Projeto de Lei do Senado n. 236, de 2012. (2012). Reforma do Código Penal Brasileiro. Brasília, DF. Recuperado de https://www25.senado. leg.br/web/atividade/materias/-/materia/106404

Projeto de Lei do Senado n. 287, de 2012. (2012). Acrescenta os arts. 128-A a 128-C ao Decreto-Lei no 2.848, de 7 de dezembro de 1940 (Código Penal) para dispor sobre o crime de interrupção de gravidez em razão de diagnóstico de anencefalia. Brasília, DF. Recuperado de https:// www25.senado.leg.br/web/atividade/materias/-/materia/106803
Projeto de Lei do Senado n. 291, de 2018. (2018). Altera a Lei no 9.263, de 12 de janeiro de 1996, que regula o § 70 do art. 226 da Constituição Federal, que trata do planejamento familiar, estabelece penalidades e dá outras providências, para revogar a vedação da esterilização cirúrgica durante os períodos de parto ou aborto e a exigência do consentimento expresso de ambos os cônjuges para a esterilização cirúrgica. Brasília, DF. Recuperado de https://www25. senado.leg.br/web/atividade/materias/-/materia/133625

Projeto de Lei do Senado n. 312, de 2004. (2004). Altera a redação do Decreto-Lei no. 2.848, de 07 de dezembro de 1.940, Código Penal, para acrescentar o inciso III ao artigo 128, incluindo entre as suas excludentes de antijuridicidade, hipótese permissiva de interrupção de gravidez. Brasília, DF. Recuperado de https://www25.senado.leg. $\mathrm{br} /$ web/atividade/materias/-/materia/70960

Projeto de Lei do Senado n. 460, de 2016. (2016). Altera o DecretoLei no 2.848 , de 7 de dezembro de 1940 - Código Penal, para criminalizar o induzimento e a instigação ao aborto e o anúncio de meio abortivo, bem como para exigir o exame de corpo de delito e a prévia comunicação à autoridade policial para a não punição do aborto resultante de estupro, e modifica a Lei no 12.845 , de 1 으 de agosto de 2013, para aperfeiçoar a redação dos arts. 1으 a 3‥ Brasília, DF. Recuperado de https://www25.senado.leg.br/web/atividade/ materias/-/materia/127777

Projeto de Lei do Senado n. 461, de 2016. (2016). Altera o Decreto-Lei no 2.848 , de 7 de dezembro de 1940 - Código Penal, para criminalizar a prática do aborto em qualquer estágio da gestação. Brasília, DF. Recuperado de https://www25.senado.leg.br/web/atividade/ materias/-/materia/127776

Projeto de Lei n. 556, de 2019. (2019). Altera o Decreto-Lei no 2.848, de 7 de dezembro de 1940 - Código Penal, para elevar a pena do crime de aborto provocado por terceiro, com o consentimento da gestante, e criar nova causa de aumento de pena. Brasília, DF. Recuperado de https://www25.senado.leg.br/web/atividade/ materias/-/materia/135119

Projeto de Lei n. 848, de 2019. (2019). Altera a Lei no 8.069, de 13 de julho de 1990, para tornar obrigatória a divulgação de informações de caráter educativo e preventivo que possam contribuir para a redução da incidência da gravidez na adolescência e alertar sobre os graves riscos inerentes à prática do aborto. Brasília, DF. Recuperado de https:// www25.senado.leg.br/web/atividade/materias/-/materia/135290

Projeto de Lei n. 2.574, de 2019. (2019). Criminaliza o aborto provocado que seja motivado pela má formação fetal. Brasíllia, DF. Recuperado de https://www25.senado.leg.br/web/atividade/ materias/-/materia/136519

Projeto de Resolução do Senado n. 54, de 2008. (2008). Altera o art. 43 do Regimento Interno do Senado Federal, para prever a concessão de 30 dias de repouso remunerado à Senadora gestante, em caso de natimorto ou de abortamento, e de 5 dias ao Senador cujo cônjuge ou companheira se encontre na referida situação. Brasília, DF. Recuperado de https://www25.senado.leg.br/web/atividade/ materias/-/materia/87649

Proposta de Emenda à Constituição n. 29 de 2015. (2015). Altera a Constituição Federal para acrescentar no art. 50, a explicitação inequívoca "da inviolabilidade do direito à vida, desde a concepção. Brasília, DF. Recuperado de https://www25.senado.leg.br/web/ atividade/materias/-/materia/120152 
Requerimento Comissão de Direitos Humanos e Legislação Participativa n.18, de 2013. (2013). Requer a realização de audiência pública para expor e debater sobre decisão daquela Entidade de praticar a interrupção da gravidez mais precisamente, da prática do aborto com 12 semanas de gravidez. Brasília, DF. Recuperado de https:// www25.senado.leg.br/web/atividade/materias/-/materia/112179

Requerimento Comissão de Direitos Humanos e Legislação Participativa n. 24, de 2015. (2015). Requer nos termos do artigo 90, inciso II do Regimento Interno, a realização de audiência pública, tantas quantas forem necessárias, para um debate amplo sobre a SUG 15, de 2014. Brasília, DF. Recuperado de https://www25.senado.leg.br/web/ atividade/materias/-/materia/119990

Requerimento Comissão de Direitos Humanos e Legislação Participativa n. 33, de 2015. (2015). Requer, nos termos regimentais, a realização de Audiência Pública nesta Comissão de Direitos Humanos e Legislação Participativa para debater o Relatório da Anistia Internacional, que revela preocupação com violência policial, abortos e impunidade no Brasil. Brasília, DF. Recuperado de https://www25.senado.leg. br/web/atividade/materias/-/materia/120140

Requerimento Comissão de Direitos Humanos e Legislação Participativa n. 36, de 2015. (2015). Requer, nos termos regimentais, a realização de Audiência Pública nesta Comissão de Direitos Humanos e Legislação Participativa, para debater a SUG 15/2014. Brasília, DF. Recuperado de https://www25.senado.leg.br/web/atividade/materias/-/ materia/120251

Requerimento Comissão de Direitos Humanos e Legislação Participativa n. 68, de 2018. (2018). Requer, nos termos regimentais, a realização de Audiência Pública conjunta da Comissão de Constituição, Justiça e Cidadania e Comissão de Direitos Humanos e Legislação Participativa no Senado Federal. Com o apoio da Comissão de Constituição e Justiça e de Cidadania; Comissão de Defesa dos Direitos das Pessoas com Deficiência; Comissão de Defesa dos Direitos da Mulher; Comissão de Direitos Humanos e Minorias; e Comissão de Seguridade Social e Família da Câmara para discutir a ADPF 442 que tramita no STF. Brasília, DF. Recuperado de https://www25.senado.leg.br/web/ atividade/materias/-/materia/132911

Requerimento de Comissão de Assuntos Sociais n. 28, de 2019. (2019). Com fundamento no disposto no art. 93, inciso II, do Regimento Interno do Senado Federal, requeremos aprovação de seminário destinado a debater as questões médicas, científicas, legais e sociais que envolvem o Zika Vírus e a microcefalia. Brasília, DF. Recuperado de https:// www25.senado.leg.br/web/atividade/materias/-/materia/136064

Requerimento n. 44, de 2019. (2019). Adiamento da discussão do PLC 115/2018 para oitiva da Comissão de Constituição, Justiça e Cidadania. Brasília, DF. Recuperado de https://www25.senado.leg. br/web/atividade/materias/-/materia/135359

Requerimento $n$. 71, de 1991 (1991). Requer, nos termos regimentais e de acordo com o art. 50, parágrafo segundo, da Constituição Federal, sejam solicitadas ao ministro da justiça, informações sobre os alarmantes de abortos fatais no brasil. Brasília, DF. Recuperado de https://www25.senado.leg.br/web/atividade/materias/-/ materia/34659

Requerimento $n .75$, de 1991. (1991). Requer, nos termos regimentais, sejam solicitadas ao Ministro da Saúde, informações sobre abortos ocorridos no país. Brasília, DF. Recuperado de https://www25.senado. leg.br/web/atividade/materias/-/materia/34696
Requerimento n. 668, de 1991. (1991). Requer nos termos regimentais, a transcrição nos anais do Senado Federal, do artigo de autoria do Dr. Helio Aguinaga intitulado 'aborto fora do útero', publicado no jornal 'O Globo', de 29 de setembro de 1991. Brasília, DF. Recuperado de https:// www25.senado.leg.br/web/atividade/materias/-/materia/38598

Requerimento n. 1067, de 2019. (2019). Oficie o Presidente do Senado Federal, no sentido de que, pelos meios oficiais pertinentes, consulte o Supremo Tribunal Federal, quanto a processos porventura em tramitação naquela Corte, que digam respeito à hipótese da prática de aborto por gestantes infectadas pelo vírus Zica. Brasília, DF. Recuperado de https://www25.senado.leg.br/web/atividade/ materias/-/materia/139997

Requerimento n. 1316, de 2020. (2020). Informações ao Ministro de Estado Interino da Saúde. Brasília, DF. Recuperado de https:// www25.senado.leg.br/web/atividade/materias/-/materia/143273

Requerimento n. 1706, de 2020. (2020). Informações ao Ministro de Estado da Saúde interino. Brasília, DF. Recuperado de https:// www25.senado.leg.br/web/atividade/materias/-/materia/143873

Ribeiro, M. S., \& Pinheiro, V. S. (2017). A dignidade da pessoa humana e o direito à vida do nascituro: fundamentos biológicos, filosóficos e jurídicos. Revista de Direitos e Garantias Fundamentais, 18(3), 139-176.

Robinson, R. (2013). Punctuated Equilibrium and the Supreme Court. Policy Studies Journal, 41(4), 654-681.

Roh, J., \& Berry, F. S. (2008). Framing and modeling the outcomes of state abortion funding referenda: morality or redistributive policy, or both? State Politics and Policy Quarterly, 8(1), 66-87.

Ryan, T. J. (2014). Reconsidering moral issues in politics. Journal of Politics, 76(2), 380-397.

Schwartz, M. A., \& Tatalovich, R. (2009). Cultural and institutional factors affecting political contention over moral issues. Comparative Sociology, 8(1), 76-104.

Secchi, L. (2016). Análise de Políticas Públicas: diagnóstico de problemas, recomendação de soluções. São Paulo, SP: Cengage Learning.

Senado Federal. (2015). Proposta de emenda à Constituição $n^{\circ} 29$, de 2015. Recuperado de https://www25.senado.leg.br/web/atividade/ materias/-/materia/120152

Senado Federal. (2016, abril 28). Sistema de Informações do Congresso Nacional (SICON). Descriminalização do aborto volta a causar polêmica em Comissão. Recuperado de https://legis.senado.leg.br/sicon/index. htmljsessionid=5EA2B368C243BE871DC8EB031BB536A7\#/basica

Senado Federal. (2018). Requerimento RDH 68/2018. Recuperado de https://legis.senado.leg.br/sdleg-getter/ documento?dm=7717787\&disposition=inline

Senado Federal. (2019, fevereiro 12). Senado desarquiva PEC que estabelece inviolabilidade do direito à vida desde a concepção. Senado Notícias. Recuperado de https://www12.senado.leg.br/ noticias/materias/2019/02/12/senado-desarquiva-pec-que-estabelece inviolabilidade-do-direito-a-vida-desde-a-concepcao

Smith, K. B. (2002). Typologies, taxonomies, and the benefits of policy classification. Policy Studies Journal, 30(3), 379-395.

Smith, K. B., \& Larimer, C. W. (2009). The public policy theory primer. Boulder, CO: Westview Press. 
Dinâmicas da agenda do aborto no Senado Federal: de 1988 a outubro de 2020
Maria Clara Figueiredo Dalla Costa Ames | Mauricio Custódio Serafim Marcello Beckert Zappellini | Andrei Costa Colonetti
Smith, T. A., \& Tatalovich, R. (2003). Cultures at war: Moral conflicts in Western democracies. Peterborough, UK: Broadview Press.

Soares, O. (1996). Pronunciamento de Odacir Soares em 01/02/1996. Recuperado de https://www25.senado.leg.br/web/atividade/ pronunciamentos/-/p/texto/180785

Souza, G., Feltrin, R. B., \& Velho, L. (2019). Audiências públicas no Senado: o direito ao aborto em disputa (2015-2016). Cadernos de Gênero e Diversidade, 5(4), 190-216.

Studlar, D. T., \& Burns, G. J. (2015). Toward the permissive society? Morality policy agendas and policy directions in Western democracies. Policy Sciences, 48(3), 273-291.

Sugestão $n^{\circ} 15$, de 2014. (2014). Regular a interrupção voluntária da gravidez, dentro das doze primeiras semanas de gestação, pelo sistema único de saúde. Brasília, DF. Recuperado de https://www25. senado.leg.br/web/atividade/materias/-/materia/119431
Supremo Tribunal Federal. (2013, abril 30). Arguição de Descumprimento de Preceito Fundamental 54. Relator Ministro Marco Aurélio. Brasília, DF. Recuperado de http://redir.stf.jus.br/paginadorpub/paginador. jsp?docTP=TP\&docID=3707334

Supremo Tribunal Federal. (2017, março 08). Arguição de Descumprimento de Preceito Fundamental 442. Relatora Ministra Rosa Weber. Brasília, DF. Recuperado de http://www.stf.jus.br/ portal/autenticacao/ sob o número 14955238

Tatalovich, R., \& Daynes, B. W. (2014) Moral controversies in American politics (4a ed.). Armonk, NY: M.E. Sharpe.

Wu, X., Ramesh, M., Howlett, M., \& Fritzen, S. (2014). Guia de Políticas Públicas: gerenciando processos. Brasília, DF: Enap.

Zappellini, M. B. (2014). Montagem de Agenda no Comitê Itajaí: uma Aplicação do Modelo de Kingdon. RAC, 18(6), 795-812.

Maria Clara Figueiredo Dalla Costa Ames

ORCID: https://orcid.org/0000-0002-0444-8764

Doutora em Administração pela Universidade do Estado de Santa Catarina (UDESC); Professora Colaboradora na Universidade do Estado de Santa Catarina (UDESC). E-mail: mariaclaraames@gmail.com

Mauricio Custódio Serafim ORCID: https://orcid.org/0000-0002-4852-5119

Doutor em Administração pela Fundação Getulio Vargas de São Paulo (FGV EAESP); Professor Associado na Universidade do Estado de Santa Catarina (UDESC). E-mail: serafim.esag@gmail.com

Marcello Beckert Zappellini

ORCID: https://orcid.org/0000-0002-8097-4547

Doutor em Administração pela Universidade Federal da Bahia (UFBA); Professor Adjunto na Universidade do Estado de Santa Catarina (UDESC).

E-mail: mbzapelini@hotmail.com

Andrei Costa Colonetti

ORCID: https://orcid.org/0000-0003-1023-9421

Bacharel em Administração Pública pela Universidade do Estado de Santa Catarina (UDESC); Pesquisador voluntário do grupo de pesquisa AdmEthics -

Ética, Virtudes e Dilemas Morais em Administração (ESAG/UDESC).E-mail: colonettiandrei@gmail.com 